\title{
Código de Ética de la Sociedad de Neurología, Psiquiatría y Neurocirugía de Chile Ethics code of SONEPSYN
}

$\mathrm{R}$ ecientemente la Comisión de Ética de SONEPSYN ha elaborado un Código de Ética para nuestra sociedad que fue aprobado por la directiva. Corresponde analizar cuál es la naturaleza y alcance que tiene este código.

Los códigos de ética (también llamados deontológicos, o de ética profesional) son documentos que recogen un conjunto más o menos amplio de criterios y normas de comportamiento de carácter moral, que formulan y asumen el compromiso de seguir quienes llevan a cabo una determinada actividad. A diferencia de los códigos de conducta que a veces regulan los aspectos más formales, concretos y superficiales de un determinado ejercicio laboral (como hábitos de trabajo, trato hacia las personas, indumentaria, horarios, etc.), los códigos deontológicos como es el Código de Ética abordan los aspectos más sustanciales y fundamentales de un ejercicio profesional, es decir, aquellos que conforman o entrañan su dimensión ética específica. Por esto mismo, este tipo de códigos son más necesarios en aquellas actividades en las que el profesional dispone de un mayor margen de decisión personal al realizar su labor y asume una mayor responsabilidad por la índole de su cometido y los efectos que éste tiene para otras personas como es el caso de la profesión médica.

\section{El Código de Ética y la formación profesional}

La falta de contenidos de Ética Médica en los programas de muchas de las escuelas de Medicina ha terminado por afectar también al proceso de formación de los médicos. Se considera que un licenciado en Medicina debe dominar o al menos estar familiarizado con los conocimientos teóricos y las tecnologías asociadas a su profesión; pero segu- ramente no se habrá planteado a lo largo de todos sus estudios los problemas éticos de esta actividad. Los futuros profesionales se forman desconociendo casi por entero las implicaciones éticas que tienen las decisiones que toman en su trabajo al cual van a dedicar en adelante la mayor parte de su tiempo. Y tampoco el entorno laboral y profesional en el que se integran favorece en la mayoría de los casos la toma de conciencia de las implicaciones éticas que existen diariamente en su trabajo.

Debido a lo anterior es necesario destacar lo que hoy debemos entender por profesional: ser alguien capaz de hacer algo técnicamente irreprochable pero también capaz de tener muy presente la dimensión moral de esa misma acción.

El médico es un profesional que cada vez más trabaja rodeado de gran variedad de recursos técnicos y, además en todo momento debe considerar la dimensión moral que tienen sus decisiones. Es necesario estar conciente que el trabajo actualmente se hace cada día más técnico y sujeto a rutinas y exigencias económicas que tienden a deshumanizarlo y a hacer perder de vista su dimensión personal. Esta es una importante función de los códigos deontológicos: permiten reconocer y asumir que el ejercicio de una profesión conlleva una serie de valores y obligaciones morales que deben acompañar y guiar su desempeño.

\section{Utilidad del Código de Ética}

La primera utilidad que conlleva el contar con un código deontológico es que supone el reconocimiento público de la dimensión ética de nuestra sociedad. Los profesionales suelen otorgar a los aspectos técnicos, estratégicos y económicos de su actividad una atención preferencial que hace que los aspectos morales queden relegados a un segun- 
do plano o sean simplemente ignorados. La dimensión ética suele estar ausente de esta imagen de lo que debe ser un buen profesional. Si pensamos que con este código se beneficiarán desde los pacientes hasta los propios médicos, pasando por los proveedores de salud, ya merece la pena tenerlo.

SONEPSYN, como cualquier otra organización de personas, no sólo es un conjunto de bienes materiales dispuestos para la obtención de unos resultados. Las personas que la integran reciben mensajes sobre la forma de ser de la sociedad y a su vez, con su actuar y con su forma de relacionarse con los pacientes, y demás, transmiten esa cultura ética hacia el exterior. El Código de Ética es una herramienta de gestión que permite definir y mantener de manera homogénea la cultura corporativa que SONEPSYN quiere transmitir como su señal de identidad.

Además, debido a que la ambigüedad en cuanto a lo que es ético puede convertirse en un problema para los médicos, los códigos de ética son una respuesta para reducir esa ambigüedad. Un código de ética es un documento formal que establece los valores principales de SONEPSYN y las reglas éticas que espera que sus socios sigan. Plantea y explica cuál es la cultura corporativa en este campo de acción.

Actualmente el Código de Ética es el medio más extensamente utilizado de auto-control ético del profesional en el campo de la Medicina en todos los países.

No a todas las actividades desarrolladas en la sociedad se les exige, a los que las practican, que cuenten con un código de conducta que exhorte a un comportamiento que vaya más allá de lo que se les pide como simples ciudadanos. A la mayoría, le basta las leyes comunes del país para regular las conductas. En el caso del médico, debido a la especial vulnerabilidad de la persona enferma, se requiere de exigencias de conductas morales superiores a las del ciudadano común. Por esta razón la Medicina no es el mero ejercicio de un oficio, sino la completa entrega de un profesional con su quehacer, debido al rol particular que la sociedad le ha asignado.

Todos estos aspectos fueron claramente deter- minados desde los inicios de la medicina como profesión en el Juramento Hipocrático:

"A cualesquier casa que entre, iré por el beneficio de los enfermos, absteniéndome de todo error voluntario y corrupción, ... Ahora, si cumplo este juramento y no lo quebranto, que los frutos de la vida y el arte sean míos... y que lo contrario me ocurra si lo quebranto y soy perjuro.”

\section{Alcances del Código de Ética}

Es de importancia considerar que los códigos deontológicos no tienen como objetivo mejorar la imagen pública de un determinado grupo profesional. No constituyen un simple ejercicio de relaciones públicas. Son la expresión escrita de la voluntad de formular reflexivamente las responsabilidades compartidas y de expresar públicamente los criterios, los valores y las finalidades que identifican a la sociedad. En el código se describe de manera explícita los mandatos que los socios deben cumplir en su desempeño profesional y las conductas que son sancionables.

Estos mandatos son guías de conducta para ser aplicadas en el trabajo del médico y que deben ser conocidas por todos los socios, además sirven como orientación para decidir ante situaciones morales complejas y, son los elementos en que se basa el Tribunal de Honor para fundamentar sus decisiones ante eventuales demandas contra algún socio.

El código deontológico contribuye de manera fundamental a crear y afirmar una conciencia moral colectiva dentro de la sociedad. Junto a los conocimientos técnicos, frente a las exigencias económicas, están también las normas y los principios morales de la profesión. A partir de ahora, con la aprobación y divulgación de esas normas éticas, ellas pueden o no ser cumplidas, pero lo que ya no pueden es ser ignoradas sin más.

Además, los valores pueden aprenderse en todo momento y un código puede acoger los aspectos morales fundamentales de la actividad profesional y de ellos derivar recomendaciones para ser aplicadas en distintas circunstancias. Por estos últimos 
motivos los códigos de ética médica constituyen hoy en día una herramienta útil en aras de la construcción de hábitos profesionales acordes con las normas morales socialmente aceptadas. Frente a los escándalos que ocurren con cierta regularidad y que son profusamente destacados por los medios de comunicación de masas, el tema del código de ética se muestra como una respuesta adecuada.

Es deseable que este Código sea ampliamente conocido y analizado por los miembros de SONEPSYN y que sea periódicamente actualizado, considerando los desafíos éticos que significan la incorporación de nuevas tecnologías y las nuevas realidades sociales.

Pero no basta contar con un código, también se requiere de un instrumento que vigile su adecuado cumplimiento. Ese instrumento es el Tribunal de Honor que se instalará próximamente en el marco del programa de modernización que está siendo objeto nuestra sociedad.

Dr. Fernando Novoa S. 